\title{
Decision Making as a Factor in Management Efficiency among Principals of Secondary Schools in Kenya
}

\author{
Nicholas M. Musau \\ School of Education, Mount Kenya University \\ Email: nimusau@yahoo.com \\ Iddah Kituyi Wanyama
}

School of Education, Mount Kenya University

Justus Mbae

School of Education, Mount Kenya University

\section{Doi:10.5901/mjss.2014.v5n5p}

\section{Abstract}

\begin{abstract}
Management of schools needs professionalism in the way decisions are made so as to cause effect towards achieving the set goals and objectives. The right decision on the way to manipulate resources is very critical and therefore Principals in secondary schools have the duty to integrate a diversity of elements so as to make good decisions within their institutions. While systematic and good decisions may cause sanity in the way operations take place in schools, haphazard and autocratic decisions may destroy any developmental focus of the school. In the Kenyan school context, a number of disturbing events have been witnessed in schools which point to the way Principals of secondary schools make decisions and how effective the decisions they make aid in the management of the institutions. Often, the decisions which Principals of schools and who are assumed to have been trained make about their schools culminate into notable differences in the way the decisions impact on the development and performance of the schools. Poor decision making has caused unwarranted strikes that have seen the destruction of property and in some cases death in schools. This study sought to establish the need to re-train both the management and the administration of schools on how to make and implement sound decisions in their schools.
\end{abstract}

Keywords: Decision making, Management, Education, Teacher, School, Policy.

\section{Introduction}

Decision making is the conscious choice from a well-defined set of often competing alternatives through the process of specifying the nature of the problem and selecting among available alternatives to solve it. Decision and behaviour may be the core characteristics of decision-making phenomena. They involve the process of human thought and reaction about the external world, which include the past and possible future events as well as the psychological consequences, to the decision maker, of those events, the essence of which decision making seems to integrate both the beliefs about specific events and people's subjective reactions to those events (Oliveira, 2007)

Theories of decision-making have been somewhat eclectic, as they demand a multidisciplinary approach to understand them (Oliveira, 2007). According to Kay (2002), it is essential to comprehend the nature and origins of human intuitions to understand the intricacies of decision making. The most outstanding characteristics of decision-making are "the decision and behaviour" that comes out of it. They involve the process of human thought and reaction about the external world, which include the past and possible future events and the psychological consequences, to the decision maker, of those events (Oliveira, 2007). This context presents decision making as the mental progression resulting in the choice of a path of action among some alternative scenarios whereby, every decision making process produces a final choice born out of a psychological construct.

Choice is the outcome of the process which involves assessment and judgement; that is, the evaluation of different options and making a decision about which option to choose. In order for these processes to take place and a choice to be made, there need to be two or more alternatives from which to choose (Beresford \& Sloper, 2008). The decision to be made will either be subjected to cause either positive or negative effect on individual, group or corporate organisations. 
The choice to be selected may be informed by emotions, information, logic, hope and creativity; all of which crowd in on the human being.

A correct decision makes the human life better and provides some control over life. However, a bad decision may force a person to result in making even another worse decision! As the problem of decision-making is in fact the problem of coping with uncertainty, which is ubiquitous, it is thought worthwhile to start with a brief passage giving an overview of uncertainty and linking it with decision making (Kozine, 2004).

The decision making process involves a series of complex intersection of events. For instance, a careful study of an existing situation involves studying the environment to see what is going on. In a school set up, it could be the study of staff activities, student affairs, parents' opinions, catering, community relations, effectiveness of available resources, etc.

The next step involves recognition and disjunction of the problem. Once an undesirable situation in the system has been noticed, the administrator seeks to identify issues that might become problems. The decision maker then makes an effort of recognising and understanding the problem in the subsequent analysis of the solution. It then follows the screening and examining the detailed make-up of the problem in the existing situation. In this context, the problem is classified on the level of magnitude.

In a case where it is a routine difficulty, the administration can apply the established mechanism and procedures for dealing with the difficulty. If it is a unique mechanism in methodology and procedures for dealing with the difficulty, the administrator can explore all ideas that are relevant to the problem. The decision maker has the liberty to involve ideas of concerned stakeholders in order to gain support of the decision to be made. To this end, decision making is a routine activity in management and the success of any institution depends majorly on the competence of the management in making decisions.

Good decision making must be taken out rather than quit. We may have great plans that have been studied and worked out in great details, but if we do not take decision to act on it, they can be of no use to us except to be sorry reminders of wasted time, lost opportunities and unrealized goals and objectives- (Sompong Yusoontorn, 2011).

Decision making forms the foundation of every management and business activity. It goes without saying; in good management, decision making and problem solving can greatly improve an organizations profits and achievement of goals and objectives which starts with a purposeful, consecutive, strategic-thinking process. Making decisions is one of the prime functions of educational management, where decisions are made in such important areas as the allocation of scarce teaching and learning resources, enrolment of students, employment of teaching and non-teaching staff, the introduction of new curriculum or curriculum reformation, student and staff discipline, staff training and methods of improving pedagogy and educational research (Okumbe, 1998). These decisions, made by institutional management are informed by the aspects of power, influence and authority. While Power enables and places the Principals in key positions to influence others to achieve organizational goals, the aspect of influence gives them the ability to use their positions in power to get what is considered acceptable. Authority on the other hand gives them the right to use power.

In organizations therefore people derive power from the positions they hold. Given the authority and rights to use power, then those with positions (like Principals) that wield power are likely to have the ability to influence the actions of their subordinates. But then, it is important to note that the subjects hereby referred to can contribute to influence positively or negatively on the decisions made in schools. Principal who value and manage wisely the knowledge among the experienced members of staff will often succeed in making decisions that will gain popular support within the institution. The school management should therefore develop appropriate decision making styles, but more importantly, the ability for the Principal to know what decision making style she/he ought to use, who to involve in making the decision even if by way of consultation and what type of decision to make.

\section{Theoretical Framework}

\subsection{The Classical Theory of Decision Making}

Classical decision theory is bounded on the assumption that decision making should adopt a rational process whereby decision makers choose the course of action that may maximize the attainment of set goals and objectives. The decisionmaking process is thus broken down into a series of sequential steps:

i) Discerning a Problem or Opportunity. This includes the perception of a problem and opportunities that gets the decision-making process started. The assumption is that problems and opportunities exist all around us, but if they are not perceived and noticed, they do not initiate the decision-making process.

ii) Formulation of Goals and Objectives. Once a problem or opportunity has been identified, the decision maker identifies the goals and objectives that a good decision should achieve. 
iii) Generate Alternatives. On successful formulation of goals and objectives, the decision maker then generates alternative courses of action that might result in attaining set goals. The decision maker should be creative and imaginative enough to generate as many alternatives as possible and should try to ensure that the set of alternatives is relatively diverse and worthy considering in the decision-making process.

iv) Gathering of Information. The next step is the gathering of information about each alternative and their likely consequences followed by systematic evaluation of the alternatives that have been gathered. The decision maker must specifically seek to learn as much as possible regarding the likelihood of each alternative resulting in the achievement of the goals and objectives being sought.

v) Assessment of the Alternatives. Once all available information has been collected regarding all of the alternatives under consideration, the decision maker must use all available information to evaluate all the alternatives in a systematic way. The outcome of this evaluation process should then be a rank ordering of the alternatives from best to worst in accordance to their likelihood of leading to the attainment of the goals and objectives of the decision maker.

vi) Selection of the Best Alternative. The decision maker simply chooses the alternative that the evaluation process has indicated to be most desirable.

vii) Implementation of the Decision. The decision-making process bares meaning once the chosen course of action is implemented. In this regard, issues of implementation are frequently important factors in the choice of an alternative in the previous stages.

viii) Evaluation of the Effectiveness the Decision. The decision maker should judge the extent to which the chosen alternative has succeeded in solving the initial problem and achieving the goals identified at the outset of the process. The evaluation indicates success or failure to solve the problem or achieved stated objectives. However, if the chosen alternative has not solved the problem or achieved stated objectives, then the decision maker recycles through the decision-making process to generate a new alternative.

In summary, the decision-making process can be divided into three major phases which includes framing the problem or opportunity, or determining exactly what the decision maker faces and the objectives to be accomplished and secondly, the generation of ideas, alternatives, and information. The final phase requires a systematic analysis reduction of the information and alternatives down to a single choice of what will be pursued and implemented.

However, Higgins, (1991), outlined some of the critical assumptions of the Classical Theory of Decision Making;

- Goals and objectives are known, agreed upon and assumed to be achieved in a situation where they are either predetermined or else so obvious as to be straightforward. Classical theory does not address itself to situations in which goals are unclear, in which disagreement exists regarding goals, or in which several goals are in conflict with one another.

- The existence of the problem is recognized, its nature has been identified, and all possible courses of action are considered. Decision makers must generate and evaluate all possible courses of action. Decision making is thus an exhaustive process in which no potential solution to a problem is excluded from consideration. The best alternative guides the decision.

- The consequences of implementing each alternative are certain, or a probability may be assigned to each and therefore all outcomes are taken into account. Classical theory assumes that decision makers are aware of and take into account every possible outcome associated with each alternative under consideration.

- The Classical Theory of Decision Making assumes acquisition of perfect information to be freely available and that decision makers either possess or can obtain (at no cost) perfect information regarding the value of every outcome that may be obtained, and also the likelihood that each alternative course of action will result in obtaining each of the outcomes.

- Decision makers will seek to maximize their situation by choosing the best alternative.

- Classical theory views decision makers as totally rational. They can assign values, order preferences, and make the decision that will optimize the attainment of the decision maker's objectives. This total rationality results in the decision maker always choosing the optimal course of action.

\section{Theories}

According to Beresford \& Sloper, (2008), theories regarding judgment, decision making and choice generally fall into two categories: normative theories of cognition and descriptive theories of cognition. Normative theories are concerned with 'How we should or ought to reason, make judgments and take decision' (Over, 2004). Theories falling into this category include formal logic, probability theory, and decision theory. Descriptive theories are set out to describe how people 
actually think when making decisions and the theories have empirical evidence to support them. However, other theorists groups decision making theories into The Rational Comprehensive Model, The Incremental Theory and The Mixed Scanning.

Quite often, problems are not always clearly defined; problems have to be formulated in a way which enables people to make decisions about them out of the vast amounts of information they might have. The problems confronting decision makers often embody conflicting values. In order to strengthen the process of making decisions, ignorance of the past decisions should be avoided because it may foreclose many important alternatives. This model of decision making assumes that there is one (unitary) decision maker, when in fact a great many people, interests and institutions (stakeholders) are usually involved.

In management of learning institutions, most processes of making decisions ought to be guided by making rational choices or based on research findings. This may perhaps adopt the rational comprehensive model which is based on the reasoning of economists, mathematicians, and psychologists. It assumes;

- That the decision maker can identify the problem.

- That the decision maker's goals, values, and objectives are clear and ranked in accord with their importance.

- That, alternative ways of addressing the problem are considered.

- That, the cost and benefits or advantages and disadvantages of each alternative are investigated.

- That, alternatives and their consequences can be compared with other alternatives.

- That, the decision maker will choose the alternative that maximizes the attainment of his or her goals, values, and objectives.

For instance, in the event a queer behaviour that touches of religious beliefs has been identified in school, the management ought to investigate its root causes by involving the students, teachers, parents and probably relevant churches in order to get informed on what kind of decision is appropriate to arrest the problem. A number of remedial alternatives may be listed and discussed so as to choose the most befitting solution to the problem.

In some instances, the school management will likely need to adopt the process of the incremental theory which involves the selection of goals and objectives; often intertwined with; not distinct from, the scientific analysis of the problem. Decision makers in this process only consider alternatives for dealing with a problem that differs marginally (incrementally) from existing policies or decisions (suggesting that they do not completely remake policy or new decisions every time they make a policy decision, but instead refashion existing policy). For each alternative, only important consequences are considered. Problems confronting the decision maker are continually redefined. Constant ends-means and, Means-ends adjustments are made to better manage policy. Seldom are there ever single decisions or totally correct solutions available to resolve a problem. Incremental decision making is remedial, not holistically-devised or futureoriented.

In some circumstances, decision makers may circumstantially use a mixed scanning approach which considers both fundamental and incremental decisions and which may incorporate a broad-based analysis sometimes and an indepth analysis at other times. It considers the differing capacities of decision makers. The approach is not very specific about how mixed scanning could be used in practice.

As stated above, Principals must make decisions that touch on the well-being of their schools. While it is desirable and democratic to include as many stakeholders as possible in making decisions, the school management whose Executive officer is the Principal bears the responsibility of the outcomes of the decisions made in the school. Their process may adopt a rational decision-making model, in which decision makers analyse a number of possible alternatives from different scenarios before selecting a choice based on important school practices. These scenarios are weighed by probabilities, and decision makers can determine the expected scenario for each alternative. The final choice would be the one presenting the best-expected scenario and with the highest probability of outcome. In economic theory, for example, the rational decision-making methodology leads to the selection of an alternative after completing a simple three-step process and which are good for school management -

Analysing the feasibility of the alternative, pondering the desirability of the alternative, and finally, choosing the best alternative by combining both desirability and feasibility (Rubinstein, 1998).

On the other hand, the normative processes of decision explain how decision makers employ a particular set of alternatives to solve problems (Goodwin \& Wright, 1998; Hoch, Kunreuther, \& Gunther, 2001). However, decision making in an organization seems to occur according to two principal models: the Classical and the Behavioural. While the classical decision theory model revolves around a highly rational, systematic, and comprehensive perspective, the behavioural theory of decision making focuses a more realistic and workable approach on the psychological and interpersonal aspects of decision making (Higgins, 1991). 
The classical model was for many years believed to be the way decisions were actually made. However, more recent studies of decision making show that the behavioural approach are the more realistic of the two. People do not always make decisions in a strictly rational manner. Psychological and interpersonal factors greatly affect the process.

\section{Policy}

Policy making is the first step in any planning cycle and planners must appreciate the dynamics of policy formulation before they can design implementation and evaluation procedures effectively. For the purposes of this paper, policy is defined functionally to mean: An explicit or implicit single decision or group of decisions which may set out directives for guiding future decisions, initiate or retard action, or guide implementation of previous decisions - Haddad, W. (1995). Policies, however, differ in terms of their scope, complexity, decision environment, range of choices, and decision criteria. Policy formulation in schools take place at different levels; national down to school level and in most cases they form the base on which other minor decisions are made to facilitate implementation. Principals are often tasked with the responsibility to study the provided policies and their implementation guidelines so as to domesticate them in their institutions.

\section{Education Planning}

The act of planning is in itself making decisions that seek to address the achievement of set goals and objectives of an institution. Planning allows for decisions to be made comfortably and in a smart way. In the school context, decisions will get four benefits out of planning:

- Planning give chance to the school establishment of independent goals. It is a conscious and directed series of choices.

- Planning provides a standard of measurement. It is a measurement of whether the school is going towards or further away from the set goal.

- Planning converts values to action. The school management plans and decides what would help advance the plan to its best.

- Planning allows for limited resources to be committed in an orderly way. It always governs the use of what is limited to the institution. (E.g. money, human resource, time, etc.)

\section{Educational Management Styles}

Management styles inform the process to the way decisions are made in schools. Whether Autocratic, democratic or Laissez-Faire, the Principal in a school must weigh the prevailing circumstances and the subjects of the decision to be made in order to make favourable decisions. The style of management affects and directs the human resource to behave in a certain way as all decisions tend to conform to the procedures of the style.

\subsection{Autocratic Management Style - (AMS)}

The style is characteristic of a manager who makes decisions unilaterally and without much regard for subordinates. According to Simon Oates (2010), AMS employs a "way of a top-down communication model". Information is passed from executives to senior management and to staff because most decision is made at "the top". The subordinates become overly dependent upon the leaders thus, requiring more supervision since decisions in the institution reflect the opinions and personality of the manager.

According to Carter MacNamara (2009), AMS presents managers who are either Directive Autocrats or Permissive Autocrats. Directive Autocrats makes decisions unilaterally and closely supervises subordinates while Permissive Autocrats makes decisions unilaterally and gives subordinates latitude in carrying out their work.

Though AMS may appear as a bad style of management, its practice may as well be credited for the dynamic way of managing time. Decisions in this style are quick and work is completed on time. Managers enjoy the privilege of dictating orders and making decisions to their staff without any consultation. On the other hand, AMS may decrease motivation and increase staff turnover because staff are not consulted and do not feel valued. 


\subsection{Democratic Management Style - (DMS)}

The Democratic style of management is one in which the manager allows employees to take part in decision making and therefore every decision is agreed by the majority. According to Carter MacNamara (2009), DMS may be classified into:

- Direct Democrats who make decisions in a participative way and closely supervises subordinates.

- Permissive Democrats who make decisions in a participative way and gives subordinates latitude in carrying out their work.

Participation in decision making gives employees a sense of belonging and motivates individuals to improve in work performance. However, it may slow decision making because the staff need to be consulted before any major decision is made. Again, some employees may take advantage of the fact that their manager is democratic by not working to their full potential and allowing other members to "carry" them. For instance, the style may allow loopholes for lazy and controversial teachers to portray the Principal as incompetent since the ultimate responsibility lies with the Principal.

\subsection{Laissez-Faire Management Styles}

In a Laissez-faire leadership style, the leader's role is peripheral and the staffs make decisions for their own areas of the business; the leader therefore evades the duties of making decisions in his/her management and uncoordinated delegation occurs. The communication in this style is horizontal, meaning that it is equal in both directions, however very little communication occurs in comparison with other styles. The style brings out the best in highly professional and creative groups of employees, however in many cases it is not deliberate and is simply a result of poor management. This leads to a lack of staff focus and sense of direction, which in turn leads to much dissatisfaction, and a poor institutional image.

\section{Findings}

The type of data collected in the study included teachers' responses on their opinion and understanding about their Principals' management practice in regard to decision making. Areas under study were the varied levels of decision making made in schools, involvement of a diversity of stakeholders in decision making and the varied procedures used by Principals to make decisions. Among the respondents, each gender; male and female was represented by $50 \%$. Majority of them were Christians with a dominance of Catholics (66.7\%) and 50\% majority were found within the age bracket of 31-35 years.

It was very clear as indicated by majority of the respondents that various decisions were made in school such as enrolment of students, allocation of resources, employment of staff, Student/staff discipline, introduction of curriculum and educational research. The respondents expressed strong opposition to the suggestion that, students are allowed to be active participants in making decisions about major operational activities like, allocation of resources, employment of staff, Student/staff discipline, introduction of curriculum and educational research in their schools. Again, not all decisions were made at the Board of Management meetings as was indicated by the $100 \%$ response affirmation by the respondents. However, while 33.3\% strongly respondent to affirm the practice of decision making as having been ratified in parents meeting before any implementation is done, another $50 \%$ disagree and $16.7 \%$ Strongly Disagree.

There was a mixed response to the suggestion that members of both teaching and subordinate staff are normally consulted in the process of making decisions in secondary schools with those who agree and Strongly Agree to the suggestion totalling $33.3 \%$ while the rest disagree (66.7\%). Respondents also disagree (83.3\%) that decisions are made in a democratic way but are sharply divided on the suggestion that decisions are made autocratically and solely by the Principal. There is very strong indication that no alternatives are put into consideration before making a choice of the best in the process of decision making.

\section{Discussion}

The findings of this study are in conformity with similar findings by Ndiku J. Mualuko, Simiyu A. Mukasa and Achoka S. K. Judy (2009) in which teachers are not adequately involved in decision making in their schools. Other than teachers, stakeholders are likely to find themselves in an environment which is characteristic of misunderstandings, mistrust and a diversity of wrangles in the schools. As indicated above, chances are that development in schools is likely to be hampered by failure to involve stakeholders in making decisions as well as the Principals being autocratic. As the 
Executive officers in schools, Principals ought to improve their skills of decision making so that they make decisions out of a number of alternatives which are rationally arrived at.

\section{Conclusion}

As per the findings in this study, it was found that Principals have not been making decisions as expected by their fellow teachers and hence, a recipe for problems in the schools. Management and in extension decision making is hereby perceived as having been a one man affair and very likely to cause the effect to retard development and performance. It is therefore very important that secondary school Principals undergo management re-training on decision making which is critically important in the process of executing responsibilities bestowed upon them.

\section{Reference}

Beresford, B. \& Sloper, T., (2008). Understanding the Dynamics of Decision-Making and

Choice: A Scoping Study of Key Psychological Theories to Inform the Design and Analysis of the Panel Study.

Berry, J. (2005). Quantitative Methods in Education Research Centre for Teaching Mathematics, University of Plymouth

Chandran, E. (2004). Research methods: a quantitative approach with illustrations from

Christian Ministries. Nairobi: Daystar University.

Goodwin, P., \& Wright, G. (1998). Decision Analysis for Management Judgment. Chichester, England: John Wiley \& Sons Ltd.

Hoch, S. J., Kunreuther, H. C., \& Gunther, R. E. (2001). Wharton on making decisions. New York: John Wiley \& Sons, Inc.

Kozine. I., (2004). Survey of decision-making theories. National Laboratory, Denmark.

Ndiku, J.M., Simiyu, A.M., \& Achoka, S. K. J., (2009). Improving decision making in Schools through teacher participation. Masinde Muliro University of Science and Technology, Kenya.

Okumbe. J.A. (1998). Educational Management: Theory and practice. Nairobi University Press.

Oliveira, A., (2007). A Discussion of Rational and Psychological Decision-Making Theories and Models: The Search for a Cultural-Ethical Decision- Making Model.

Over, D. (2004). Rationality and the normative/descriptive distinction, in D.J. Koehler and N. Harvey (eds), Blackwell Handbook of Judgement and Decision Making, Blackwell, Oxford pp. 3-18.

Rubinstein, A. (1998). Modelling Bounded Rationality. Cambridge, MA: The MIT Press.

Yusoontorn. S., (2011). Principles of Decision Making. 
